\title{
LER CABO VERDE: NOTAS E REFLEXÕES
}

\author{
ILÍDIO DO AMARAL ${ }^{1}$
}

Começaremos estas notas de leituras de publicações recentes que tivemos a ocasião de analisar, juntando algumas reflexões pessoais, pelo livro dos italianos Augusto Cusinato, Enrico Fontanari e Adriano Varotti, Praia. Una capital in formazione (Liguore Editore, Nápoles, 2001, 209 p., número 14 da colecção Societá, Territorio e Ambiente), contribuição dos Departamentos de Planificação e de Urbanística do Instituto Universitário de Arquitectura de Veneza. Os três autores partilharam entre si a composição do livro, pela ordem seguinte: Cusinato, Tra grandi opzioni e piccole dimensioni, VAROTTI, Un programma non concluso di cittá capitale. Dagli attributi della città alle proposte per i quartieri popolari e Fontanari, Una città tra conservazione e transformazione. Progetto urbanistico per due aree centrali, relevelando o carácter paradoxal da Praia, cidade com cerca de 106.000 habitantes que, por este valor, adquire a qualidade de macrocéfala num pequeno país insular constituído por dez ilhas e oito ilhéus de origens vulcânicas somando $4.033 \mathrm{~km}^{2}$ e cerca de 435.000 habitantes em 2000 e também o contraste entre a sua dimensão e o papel de ponto nodal na rede de relações que abrange três continentes, a África, a América e a Europa.

Sobre o pequeno planalto central, conhecido, localmente, desde tempos remotos por Platô (32ha), concentra-se o máximo de instituições da administração estatal, a presidência da república, a maioria dos ministérios, os bancos, as direcções das principais empresas públicas, a câmara municipal e seus diversos serviços, o palácio de justiça, os tribunais, o quartel militar, o bispado, a catedral, escolas, sedes de empresas privadas, o mercado municipal, uma enorme variedade de estabelecimentos comerciais, incluindo os de hotelaria e restauração, e ainda habitações, etc. A Independência em 1975 e o frenesim que se seguiu modificaram, radicalmente, não só o funcionamento do centro histórico, assinalando, de maneira simbólica e irreversível, o ingresso do País na modernidade, como também as zonas periféricas, em expansão acelerada, e modos desarticulados de crescimento interno.

Outro paradoxo é o da maior cidade ser a capital deficitária de um país carecido de recursos naturais à procura de desenvolvimento económico. Mas se, por um lado, não constitui um caso singular, tendo em conta que essa é a situação das capitais dos países africanos, todas elas com demografias avolumadas pela imigração rural e dependentes, em certa medida, de participações importantes da ajuda externa e das remessas de emigrados, por outros lado, no caso da Praia acresce a falta de uma área agrícola próxima capaz de abastecer a cidade com regularidade e suficiência, como também não há um hinterland fornecedor de produtos de valor económico para a exportação.

1 Professor Catedrático Jubilado da Universidade de Lisboa. Director do Centro de Geografia do Instituto de Investigação Científica Tropical. 
Nas ilhas vulcânicas não existem recursos minerais rendíveis e as suas posições sahelianas não favorecem a formação de aquíferos pois as chuvas são relativamente escassas, concentradas em pequeno número de meses do ano; mas, mais do que isso, são muito irregulares, ao ponto de haver anos sucessivos sem que se registem quedas de água. A estas crises climáticas, que sempre marcaram a história do arquipélago, impedindo, total ou parcialmente, o crescimento de plantas, ligam-se défices alimentares que no passado causaram milhares de perdas de vidas e obrigaram muitos cabo-verdianos a trocarem as suas ilhas por outros destinos no mundo.

Todavia, não obstante o défice alimentar, a falta de produtos exportáveis, o facto da necessidade de ajudas externas, etc., a Praia afasta-se dos paradigmas das cidade pobres ou das cidades corroídas pela decadência resultantes de má gestão urbana. São evidentes os testemunhos de planos de crescimento e modernização, da procura de resolução dos problemas que afectam serviços de base, como os do fornecimento de água, de energia eléctrica, de saneamento.

Se a Praia é África, pela sua situação geográfica, afasta-se dela pelas origens histórica e cultural. É uma cidade de fundação europeia, no caso portuguesa, em breve dominada por mestiços ou crioulos, do cruzamento de brancos e pretos, mas que não conheceu a mesclagem de instituições europeias com instituições africanas que ainda hoje marca as cidades do continente.

A Praia vive o paradoxo representado pela sua pequenez e os desígnios ambiciosos de programas definidos pelo governo nas Grandes Opções do Plano 1997-2000, documento fundamental da política económica de Cabo Verde onde intervêm a defesa do passado e o caminho da modernização, o viver da benevolência dos seus filhos emigrados e da cooperação internacional e os programas de desenvolvimento necessitados de cobertura económica e financeira, entre uma dimensão de vida inelutavelmente provinciana, dados os limitados números em jogo, e as distâncias que a separam das outras ilhas e de outros países próximos, e ainda o desejo de ser um elo de ligação entre os três continentes.

Qualquer projecto urbano relacionado com a Praia constitui um desafio aliciante pois significa tentar conciliar extremos, o possível com o impossível, manter em vida os paradoxos e, ainda, harmonizar as prospectivas do grande e do pequeno, da estratégia geopolítica e das tradições locais. São estes os desafios que tornam atraente a leitura de Praia. Una capital in formazione, esperando os autores que o seu livro tenha utilidade, não apenas para orientação dos intervenientes da administração local, mas ainda porque se esforçaram por oferecer questões objectivas para uma discussão mais lata sobre o futuro da cidade. Procuraram fazer um discurso analítico desdobrado numa pluralidade de dimensões, da história à economia, da antropologia à demografia, da geografia à sociologia e, naturalmente, da arquitectura ao urbanismo. Só é estranho que, tendo trabalhado na Praia, no outono de 1998, em colaboração com a Câmara Municipal local e outras instituições, tendo utilizado documentos de arquivos, sejam demasiado escassas as referências a estudos e relatórios publicados por investigadores portugueses. Das 235 notas de rodapé, a maioria remete para autores italianos, franceses e ingleses, contando-se pelos dedos de uma mão os portugueses.

O livro tem numerosa ilustração (quadros com valores estatísticos, figuras, estampas e documentos cartográficos), sendo de realçar as plantas a cores das pp. 187-207. Pena é que, por demasiado reduzidas, às dimensões da mancha de página, isso prejudique a sua legibilidade. Não resistimos a fazer a sua listagem, ainda que longa, porque elas revelam pormenores dos levantamentos de vários aspectos importantes, desde a reprodução de uma planta histórica de 1778 , às plantas com a representação do crescimento de áreas urbanizadas (desde 1969 a 1997), da tipologia dos edifícios, da rede viária, de actividades 
comerciais e produtivas, de zonas homogéneas, de anos de construção de edifícios, do número de pisos, do estado de conservação dos edifícios, da utilização dos lotes, da utilização do piso térreo, da utilização do primeiro andar, do número de alojamentos por edifício, do título de propriedade e usufruto, da utilização da rede eléctrica, da utilização da rede de abastecimento de água, da existência de casa de banho e outros serviços higiénicos, da rede de esgotos. Em seguida vêm as plantas com as propostas de plano estrutural (áreas edificadas e distribuição geral de actividades económicas e sociais, zonas verdes, etc.), hierarquia viária, dos serviços e espaços públicos, e das modalidades de intervenção urbanística; a última figura corresponde a um esquema de organização viária.

Sobre a Praia foi apresentada uma dissertação de mestrado no departamento de Geografia da Faculdade de Letras da Universidade de Lisboa, pela geógrafa cabo-verdiana Judite do Nascimento, docente do Instituto Superior de Educação de Cabo Verde: O Crescimento urbano e a estrutura funcional da cidade da Praia (2003, 186 p. e abundante ilustração, muita dela a cores). Depois de uma introdução, as matérias estão distribuídas por quatro capítulos assim intitulados: Teorias e modelos urbanos; conceitos de base. Caracterização geral da cidade da Praia. O crescimento urbano e a diferenciação social do espaço. A estrutura funcional da cidade da Praia.

De Carlos Ferreira Couto é Estratégias Familiares de Subsistências Rurais em Santiago de Cabo Verde, cuja primeira versão foi a de dissertação de mestrado em Estudos Africanos apresentada no Instituto Superior de Ciências do Trabalho e da Empresa. Premiada pelo Instituto de Cooperação Portuguesa, a este se deve a impressão em livro de 281 p., volume 2 da «Colecção Teses», dado à estampa em 2001.

No prefácio, o Presidente daquela instituição, depois de assinalar que se assistia, nestes últimos anos, a um renascimento dos estudos sobre África em Portugal, considerou essa renovação de bom augúrio e o trabalho de Couto como inserido numa área de crescente dinâmica e abertura intelectual, um excelente presságio não só para a academia, como para a própria relação entre Portugal e os Estados africanos independentes, particularmente os de expressão portuguesa. Mais adianta a mesma personalidade, a fascinante visão panorâmica das opções que se colocam num mundo rural descapitalizado, ligado ao mundo tanto por vias das políticas macro-económicas que o país adopta, como por via da experiência imediata da emigração e do retorno, um mundo que está no entanto profundamente enraizado na sua própria história. C. Couto recusa a simplicidade enganadora das explicações monocausais, compreendendo e fazendo compreender a necessidade de adoptar uma abordagem sincrética para a análise de pessoas que, como nós todos, são complexas no seu comportamento social. Apoiamos inteiramente estas palavras e louvamos a obra e o seu autor, investigador exigente e trabalhador incansável, quer em investigações no terreno, quer em numerosas consultas bibliográficas e ainda em muita reflexão pessoal.

A primeira parte, Considerações teóricas e delimitação do universo estudado (pp. 35-91) contém dois capítulos: Abordagem teórica, principais conceitos e considerações de métodos na pesquisa empírica, isto é, quanto ao trabalho de campo desenvolvido e Delimitação do universo empírico observado: uma comunidade rural de Santiago de Cabo Verde, dos pontos de vista físico e social. A segunda, muito mais longa, Análise e pesquisa empírica (pp. 93-263), engloba cinco capítulos: Considerações sobre a estrutura familiar, com relevo para a categoria de chefe de família, relativamente às suas actividades; As actividades de cultivo e a cooperação no trabalho, tendo em conta o sequeiro e o regadio, a estruturação social em que assenta a cooperação no trabalho (os casos tradicionais de djunta mon e de djuda) e a sua relação com o processo de assalariado; A criação de animais e a venda 
de produtos, tentando demonstrar a natureza funcional de um bem escasso (proteínas) e a natureza esporádica da venda de produtos em fases precisas do ciclo agrário; As frentes de alta intensidade de mão-de-obra e as estratégias familiares, numa perspectiva histórica e institucional e a sua articulação com as estratégias de subsistência; e A emigração, a sua importância e natureza no quadro da (re)produção da subsistência. Bastam estes enunciados e alguns complementos para mostrarem a amplidão do trabalho onde tudo é tratado com muito rigor, desde a análise de textos fundamentais de uma bibliografia vasta aos procedimentos no terreno uma vez escolhido, criteriosamente, o seu objecto de estudo: uma comunidade rural na bacia hidrográfica de Água de Galo, no vale de São Domingos da ilha de Santiago.

Couto, na cola de ilustres especialistas, traçou o quadro geral das suas preocupações aludindo ao facto de ao longo desta segunda metade do século passado, as estratégias de desenvolvimento dirigidas para o continente africano não parecerem ter produzido efeitos sinergéticos que pudessem afastá-lo da situação crítica que caracterizava as conjunturas dos diversos países, nomeadamente dos subsarianos, situação que levou, por um lado, a um impasse do desenvolvimento económico caracterizado por uma dependência externa desmesurada, urbanização galopante e desemprego estrutural; e, por outro, à estagnação agrícola associada a uma preocupante degradação dos solos, fomes e défices crónicos de produção de bens alimentares, aumentando a dependência externa dos países africanos para a satisfação das necessidades de consumo em bens alimentares essenciais. E, infelizmente, essa estagnação não teve a contrapartida de industrialização, dada a ausência de tecido industrial, de meios de financiamento e de capacidade tecnológica. A partir das suas pesquisas pode relevar a complexidade da sociedade rural santiaguense, cujo estudo exige a reconstrução de categorias de natureza não univoca ou sub-categorias que compõem formas de existência que tomam, frequentemente, configurações paradoxais e contraditórias. Ainda segundo as suas palavras, verdadeiro palco de sincretismos e reacçóes adaptativas, a sociabilidade espontânea do rural santiaguense é a condição mesma da capacidade de auto-organização e de adaptação das comunidades aos efeitos estruturantes/desetruturantes do megaprocesso da mundialização (globalização/glocalização). Não se pode falar de uma subsistência rural ou de um 'modo de produção', ou ainda de uma 'articulação' de modos de produção, sendo mais plausivel defender a probabilidade de vários 'modos de subsistência' (social e económica) numa sociedade em processo de 'desagrarianização'. Os actores sociais recorrem a várias fontes de subsistência (autoconsumo, mercado, salariado, assistencialismo e migração) num complexo processo, sempre combinatório, não linear e interaccional.

A propósito de muitas palavras contidas nesta citação, é de assinalar que C. Couto inclui no seu livro termos e conceitos que enxameiam os textos sociológicos e económicos sobre os países em desenvolvimento e têm alimentado discussões. Sublinhemos os exemplos de globalização e glocalização, autoprodução e subsistência, subsistência de natureza transversal (ligando autoconsumo, mercado, salariado, assistencialismo e migração), resilência e optimização, modernização e/ou retradicionalização, relocalização, mundos vivenciais, visões do mundo ou perspectivas mentais, desagrarianização, etc., etc., visto este último como processo de reorientação económica, de ajustamento ocupacional e de realinhamento espacial ou residencial, que afasta as populações dos padrões agrários, tendo em conta que isso tem lugar num contexto subsariano onde as relações de mercado são pouco generalizadas e a diversificação intra-sectorial muito limitada, não permitindo a especialização ocupacional dos agregados e dos indivíduos, como já definiram outros autores. O livro de C. Couto, abordando temas da maior importância, num quadro de ligações da investigação com o desenvolvimento, merece leitura atenta. 
O geógrafo Fernando Lagos Costa, Mestre em Geografia Física pela Universidade de Lisboa, Assistente de Investigação do Instituto de Investigação Científica Tropical (IICT) colocado no Centro de Geografia, submeteu-se à prova para um lugar de Investigador Auxiliar com uma dissertação intitulada Evolução geomorfológica Quaternária e dinâmica actual na bacia da Ribeira Seca - Santiago Oriental, Cabo Verde (Lisboa, 2002, vii + 269 p.), profusamente ilustrada com 62 figuras (perfis topográficos e geológicos, esboços cartográficos de pormenor, etc.), 40 fotografias a cores e numerosos quadros. Um júri constituído por investigadores do IICT de domínios afins da Geografia e Doutores nesta disciplina da Universidade Nova de Lisboa e da Universidade de Coimbra atribuiu-lhe a classificação máxima. Neste momento o autor prepara o volume para impressão definitiva.

As matérias estão distribuídas por três capítulos com as suas subdivisões: I. Características da bacia hidrográfica da Ribeira Seca; II. Traços da geomorfologia e dinâmica Quaternária dos principais vales da bacia da Ribeira Seca e III. Processos e dinâmica actual na bacia da Ribeira Seca. Segundo o autor, logo nas primeiras linhas da Introdução, a avaliação das condições Quaternárias e actuais de ocorrência dos processos de evolução natural pode contribuir para o estabelecimento de medidas de ordenamento sustentado do território que permitam evitar ou atenuar os impactos resultantes da acção desses processos e ainda os de actividades humanas. Como seria de esperar numa dissertação em instituição de investigação científica com forte componente de aplicação (I\&D), a escolha do tema e da área de trabalhos de campo tiveram em conta a prestação de serviço útil; a bacia da Ribeira Seca, pela sua extensão, pela densidade de ocupação humana e labores agrários justificou a preferência que lhe foi dada.

No primeiro capítulo o autor procurou juntar dados novos sobre a geologia (litologia e tectónica) e definir as principais unidades geomorfológicas da bacia hidrográfica e o seu enquadramento no contexto da ilha. Naturalmente que, sendo o objectivo o estudo de fenómenos de erosão, teve em conta as condições climáticas, sobretudo as que se referem à precariedade e irregularidade de chuvas e às coberturas vegetais, próprias de clima saheliano insular. O segundo capítulo contém a caracterização de aspectos topográficos de três dos vales mais extensos da bacia, a partir do comportamento dos seus perfis longitudinais e transversais. São estudados vários níveis de terraços aluviais e rochosos, estabelecidas as correlações dos primeiros com níveis de deposição marinha, sistematizadas as etapas da evolução dos vales, apresentadas algumas propostas de datas prováveis com base em critérios geomorfológicos e na comparação com a cronologia estabelecida noutras regiões, nomeadamente da África Ocidental. No terceiro capítulo, depois de uma referência à classificação portuguesa mais recente de movimentos de materiais em vertentes, o autor contribui para o conhecimento da dinâmica actual na área em estudo, definindo uma tipologia dos processos erosivos, bem como a sua distribuição espacial.

Como já foi referido, a dissertação acentua as ligações entre investigação e sua aplicação, e em muitos pontos procura mostrar exemplos de erros de certas experiências para a retenção e conservação de solos, de importância fundamental numa ilha sob condições sahelianas, e sugere correcções e outras medidas fundadas no conhecimento adequado das formas e dos processos de erosão.

Ainda com base na bacia hidrográfica da Ribeira Seca foi criado um projecto interdisciplinar intitulado Ordenamento Regional e Desenvolvimento Rural: factores de degradação e conservação dos solos na ilha de Santiago, Cabo Verde, no âmbito do Apoio à reforma das instituições públicas ou de interesse público de investigação, financiado através do Programa de Intervenção nos Laboratórios de Estado. Na equipa participaram geógrafos (climatologia e geomorfologia), geólogos (cristalografia e mineralogia), pedólogos (solos e vegetação) e agrónomos (sociologia rural) de Centros do IICT, tendo havido também colaboração de investigadores e instituições de Cabo Verde. 
De 2001 é o Dictionnaire Encyclopédique et Bilingue Portugais-Français Cabo Verdel Cap-Vert. Particularité de la langue portugaise en Afrique, organizado por FrançoIse MASSA e JEAN-Michel MASSA, com a ajuda de vários colaboradores (edição de Pédagogie, Cultures, Litératures Lusographes, Rennes, 400 p. e abundante ilustração gráfica, a maior parte dela a cores). É o volume terceiro de uma colecção que já conta com os dedicados à Guiné-Bissau (1996) e a São Tomé e Príncipe (1998), estando em preparação os de Angola e Moçambique.

As primeiras oitenta páginas do volume comportam uma abertura com uma lista cronológica, muito resumida, dos principais acontecimentos que, na opinião dos autores, eminentes especialistas de estudos lusófonos, marcaram a história de Cabo Verde desde 1415 a 2001, e de tópicos de uma espécie de bilhete de identidade do arquipélago (geografia, a terra e os homens, sociedade, organização administrativa, vida internacional, etc.). Segue-se uma Introdução (pp. xvii-xxiv) na qual é sublinhado o facto de ter havido a preocupação da utilização da língua portuguesa escrita em África e do crioulo na elaboração do dicionário enciclopédico. Desejam os seus responsáveis que ele sirva de instrumento de trabalho, de obra de referência e útil para o ensino nas línguas francesa e portuguesa.

O volume está organizado em duas partes: uma longa Apresentação com notas sintéticas sobre a geografia, a história, as línguas, as culturas, as literaturas, os homens, as sociedades, as especificidades de Cabo Verde, seguindo-se o Dicionário Enciclopédico propriamente dito, no qual foram inseridos dados biográficos de cerca de 400 personalidades, cabo-verdianos e não cabo-verdianos, ligadas à vida do arquipélago. O volume encerra com uma vasta lista bibliográfica de obras consultadas (pp. 211-280). Juntar na mesma obra, em 400 páginas, um dicionário e uma enciclopédia, com a pretensão de ser de consulta fácil e útil, certamente que não foi tarefa fácil. Mas ela teve de se conformar com as experiências já feitas nos outros dois volumes da colecção dedicada aos Países Africanos de Língua Oficial Portuguesa. As críticas que possam recair sobre os volumes não diminuirão a sua importância, sobretudo porque não existem outros empreendimentos do mesmo género. F. Massa e J.-M. Massa, bem como os seus colaboradores, merecem os nossos aplausos.

Cabo Verde, com uma posição de encruzilhada entre três continentes, nó de comunicações em que as influências recebidas e assimiladas são muito numerosas, oferece aspectos ricos e diversos, impostos pela geografia, pela história, pela economia. No Dicionário Enciclopédico a par dos vocábulos portugueses houve o cuidado de ter em conta os fenómenos de insularidade e insularismo para a selecção dos de crioulo(s), procurando encontrar não só os termos próprios a cada uma das ilhas, mas também os vocabulários particulares das duas maiores cidades, a Praia e o Mindelo, centros culturais de relevo, berços de importantes movimentos artísticos, sobretudo literários, que têm dado a Cabo Verde um lugar particular definido, pode-se dizer, pela sua cabo-verdianidade. O corpus da pesquisa foi constituído por textos escritos, impressos, obras literárias compreendidas, mas sem a preocupação de fazer um dicionário literário, e respeitadas as ortografias encontradas. São clássicas nas situações de diglossia ou bilinguismo. Em registos diferentes (rural, urbano, marítimo, etc.) os escritores nacionais, escrevendo em português, têm utilizado algumas centenas de termos crioulos - vejam-se, por exemplo, os casos dos prosadores Baltazar Lopes, Manuel Lopes, Henrique Teixeira de Sousa, Germano de Almeida e muitos outros.

Vão demasiado longe os tempos em que o crioulo, gerado a partir do século XVI, do cruzamentos de europeus com africanos que colonizaram as ilhas, e tornado língua franca, de utilização generalizada, era tido como uma corruptela ridícula do português, 
segundo um testemunho em documento de finais do século XVIII; uma alagaravia mestiça de termos africanos e de português antiquado, ..., sem gramática, sem regras fixas, escrito em monografia de meados do século XIX; e que o seu uso devia ser proibido por meios coercivos, se fosse necessário, nos edifícios públicos e em actos oficiais, conforme declaração feita em Congresso da primeira metade do século XX.

Tudo se modificaria, sobretudo a partir das teses de licenciatura de BALTAZAR LoPEs, O dialecto crioulo de Cabo Verde, publicada em 1957, e de Maria Dulce de Oliveira Almada, Cabo verde. Contribuição para o dialecto falado no seu Arquipélago, publicada em 1961. Ainda que se continuasse a usar a palavra dialecto, o crioulo estava a caminho de ganhar direitos de cidadania. Saltando no tempo e sobre numerosos escritores e músicos que utilizaram o crioulo (textos originais, traduções de poetas portugueses, incluindo Luís DE CAMÕEs, edição de uma versão da Bíblia, etc., textos de mornas, coladeiras e outras formas musicais cabo-verdianas) recordamos, de Manuel Veiga, Diskrison Strutural di Lingua Kabuverdianu, 1982, que constituiu, segundo a opinião autorizada de Dulce Almada, um passo decisivo para a redacção da primeira gramática de carácter pedagógico a utilizar nas escolas de Cabo Verde.

O Decreto-Lei 67/98, de 31 de Dezembro, do Conselho de Ministros da República de Cabo Verde definiu, claramente, a posição do crioulo como língua nacional (Boletim Oficial, I Série, n. ${ }^{\circ}$ 48-Suplemento, 31 de Dezembro de 1998, pp. 18-23) e aprovou as Bases do Alfabeto Unificado para a Escrita do Crioulo Cabo-verdiano (ALUPEC). No intróito se reconhece que a situação linguística em Cabo Verde caracteriza-se pela existência de duas línguas com estatutos e funções diferenciados: o Português como língua oficial e internacional e o Cabo-verdiano (ou o Crioulo) como língua nacional e materna, estando reservadas ao primeiro as funções de comunicação formal - a administração, ensino, literatura, justiça, mass media e ao segundo as de comunicação informal, particularmente o domínio da oralidade; que sendo o Crioulo a língua do quotidiano em Cabo Verde e elemento essencial da identidade nacional, o desenvolvimento harmoniosos do País passa necessariamente pelo desenvolvimento e valorização da língua materna, o que implica, como primeiro passo, a estandardização da escrita do Crioulo ou seja da Língua Cabo-verdiana, pela existência de um alfabeto unificado, aprovado a título experimental. É caso para recordar um aforismo popular dizendo que do tempo de Portugal havia uma língua que governava, a portuguesa, e uma língua que reinava, a crioula.

Voltando ao Dicionário Enciclopédico dirigido por F. MAssa e J.-M. MASsa, os inventários de vocabulário revelaram um número de palavras desconhecidas do português, quer pela forma, que pelo sentido, o que dá ao volume o carácter de um vocabulário de dificuldades da língua portuguesa encontradas em textos escritos por cabo-verdianos. Não se trata de um dicionário normativo do bom português, nem sequer de pronúncia. Apenas da língua escrita. Os responsáveis evitaram as discussões etimológicas, salvo talvez numa dúzia de casos, de étimos evidentes e claros, conscientes de que a etimologia cabo-verdiana ainda é um assunto pouco aprofundado. Claro que, como já referimos anteriormente, a tarefa não foi e não é fácil. Basta ter em conta que o cabo-verdiano não se define nem por referência étnica, nem pela cor, mas antes por uma pertença quadrupla: a uma nação (este sentimento é profundo e forte) partilhada no território arquipelágico e nos seus prolongamentos na diáspora; a um povo que, apesar de contido em parcelas separadas pelo mar, tem um sentimento identitário vivido intensamente, numa certeza sem arrogância; ao facto de em cada cabo-verdiano poder haver uma ilha-nação, uma ilha-povo, uma ilha de nascença ou de referência, cada uma com as suas particularidades, a sua singularidade. 
Em 2002 foram publicadas obras do maior interesse sobre o crioulo, de que destacamos duas: o Dicionário Prático Português-Caboverdiano (variante de Santiago)/Disionári Portugués-Berdiánu (Kirioli di Santiago) ku splikason di uzu di kada palábra, organizado por Mafalda Mendes, Nicolas Quint, Fátima Ragageles e Aires Semedo, e editado em Lisboa por Verbalis, 2002, 485 p., com 4085 vocábulos do português básico e 16.257 traduções para o cabo-verdiano, na variante de Santiago. Em 1998 a mesma editora já tinha produzido o Dicionário Caboverdiano-Português (variante de Santiago).

Lugar destacado merece também o livro de Dulce Almada Duarte, Bilinguismo ou Diglossia? As relações de força entre o crioulo e o português na sociedade cabo-verdiana (Praia, Edições Spleen, 1998, 288 p.), premiado pela Associação de Escritores Cabo-verdianos. Autora de importantes estudos sobre o crioulo de Cabo Verde, desde a sua dissertação de licenciatura, de 1961, neste livro, segundo as suas palavras, reúne trabalhos elaborados num período de tempo que medeia entre 1977 e 1994. Trata-se de uma selecção de diversos estudos de natureza sociolinguística apresentados em diferentes congressos, conferências, colóquios, seminários, mesas-redondas. E, assim sendo, os temas variam em função do evento ao qual se destinavam, mas obedecendo à lógica de um mesmo fio condutor. O primeiro estudo, Em Cabo Verde, a vida decorre em crioulo, pode considerar-se também uma homenagem a Jorge Amado, pois lhe pertenceu a frase que serve de título. Seguem-se Crioulo de Cabo Verde: sua génese, sua evolução texto de 1983, refundido em 1986, mas que permaneceu inédito; $O$ crioulo, expressão da identidade cultural do caboverdiano, a contribuição mais longa do livro; A história da escrita em Cabo Verde, estudo de 1993-1994, no quadro de um trabalho de equipa da Comissão Nacional para a Língua Cabo-verdiana, só agora publicado; Uma nova pedagogia do ensino do português em Cabo Verde, comunicação apresentada ao XV Congresso de Linguística e Filologia Românica, Rio de Janeiro, 1977, publicado na revista Raízes 2, e Ensino e aprendizagem do crioulo como língua materna, comunicação ao Colóquio sobre a Problemática do Estudo e da Utilização do Crioulo, Mindelo, 1979. A fechar o volume há ainda uma comunicação apresentada à IV Mesa Redonda Afro-Luso-Brasileira, Praia 1994, com o título de Língua e literatura em Cabo Verde: uma relação problematizante.

Cabo Verde, fazendo parte da África, afasta-se dos países continentais e dos seus congéneres insulares pelo facto primordial de nunca ter tido conflitos belicosos no seu interior. Não obstante as vicissitudes geográficas e históricas, dos europeus e africanos que o colonizaram cedo se constituiu uma sociedade mesclada, fruto de uma assimilação que em nenhum lugar foi tão profunda, tão complexa, tão precoce, como escreveu OrLANDo Ribeiro em 1954. Colónia enteada, como muitos lhe chamaram, mantida pobre como pobres são os seus recursos naturais, obteve a Independência em estado de serenidade e a democracia enraizou-se, com base num sentimento profundo de crioulidade. O poeta Ovídio Martins sintetizou isso nas seguintes palavras sentidas: Chamámos uma vez a Cabo Verde 'estrela salgada de dez braços, e em cada braço uma esperança'. Se pusermos hoje, em cada esperança mil certezas, ficaremos com uma ideia clara do espírito com que se enfrentam as dificuldades nesta pátria do meio do mar. Devagar, a reconstrução nacional avança. Dor a dor. Amor a amor.

Num continente rico de recursos naturais, mas de forte instabilidade política associada a processos altamente lesivos de corrupção, que o mantêm em subdesenvolvimento crónico, o pequeno estado de Cabo Verde é como que um oásis para os estudiosos de diversos domínios do conhecimento. No contexto do país insular, a vida flui serenamente, os serviços públicos e privados funcionam com normalidade, os planos e projectos de desenvolvimento são levados a cabo, as instituições internacionais confiam nos governos. 
Apraz-nos relevar esses aspectos importantes para referenciar a existência, por exemplo, de estatísticas e informações minuciosas e actualizadas de diferentes sectores. Vejamos alguns casos.

Tendo a demografia em Cabo Verde uma importância fundamental, pelos seus condicionamentos geográficos, económicos e sociais, os recenseamentos e previsões são feitos com grandes pormenores, de acordo com normas internacionais e o mesmo sucede com as estatísticas de vários sectores. Seleccionamos o exemplo do Inquérito demográfico e de saúde reprodutiva. Cabo Verde 1998, Praia, 2000, 217 p. e numerosos anexos (questionários do Inquérito), relatório final do Instituto Nacional de Estatística de Cabo Verde, pois é um documento precioso. Contou com apoios financeiros do Fundo das Nações Unidas para as Actividades em Matéria de População (FNUAP), da Associação Cabo-verdiana para a Defesa da Família (VERDEFAM), do próprio Governo de Cabo Verde, da United States Agency for International Development (USAID), da International Planned Parenthood Federation (IPPF) e do Fundo das Nações Unidas para a Infância (UNICEF), e ainda com a assistência técnica da Sociedade Civil Bem Estar Familiar do Brasil (BEMFAM) e do Centro para o Controlo e Prevenção de Doenças (CDC) de Atlanta, Geórgia (EUA).

Basta olhar o índice de matérias, distribuídas por doze capítulos, para se ter a noção da sua importância: Apresentação do País e do quadro do inquérito; Características gerais da população e dos alojamentos dos agregados familiares; Experiência de gravidezes; Fecundidade; Anticoncepção; Nupcialidade, comportamento sexual e exposição ao risco de gravidez; Intenções reprodutivas e planeamento da fecundidade; Adultos e jovens; Mortalidade das crianças menores de cinco anos; Saúde da mulher e da criança; Amamentação da criança e Doenças sexualmente transmissíveis e SIDA. Seguem-se três apêndices sobre desenho e factores de ponderação da amostra, estimativas dos erros de amostragem e elaboração do índice de conforto.

Segundo as palavras do Vice-Primeiro Ministro de então no prefácio do volume, o documento constitui um dos indicadores seguros da aposta do Governo na reforma do sistema estatístico nacional e na realização dos objectivos da Política Nacional de População. Foi o primeiro inquérito do género efectuado em Cabo Verde, através de entrevistas com mulheres dos 15 aos 49 anos e homens de 15 aos 54, dado que estes são também fundamentais na tomada de decisões em matérias de planeamento familiar: a população feminina constitui $54 \%$ da população total e a masculina os restante $46 \%$, o que representa uma relação de masculinidade de 85 homens para cada 100 mulheres, diferença que pode ser atribuída, em parte, à emigração masculina. O documento também põe em evidência grandes desafios que se colocam ao Estado e à sociedade cabo-verdiana em áreas da saúde, da educação e da comunicação.

Alguns guias de Cabo Verde, como o Anuário 2002/2003 Empresas e Instituições de Cabo Verde (Mindelo, Marktest CV) e o Guia das ONG de Cabo Verde (Praia, Plataforma das ONG, Março de 2002), oferecem amplas informações. O primeiro, em tamanho A4, é um volume graficamente muito atraente, de 176 páginas, ilustrado com muita cor, bom design e dados de pormenor sobre empresas e instituições nas áreas da agricultura, do comércio, da indústria, dos serviços e do turismo, a que se segue um caderno especial da oferta de serviços pelas ilhas Canárias, consideradas como um vizinho muito rentável (pequenas notas escritas e indicadores económicos), a lista de empresas de $\mathrm{A}$ a $\mathrm{Z}$ e a lista dos e-mail. Como escreveu o Director Geral da Marktest $C V$ na Nota de Abertura, a globalização da economia e o advento da sociedade da informação engendram, e ainda mais no futuro, mudanças na paisagem empresarial cabo-verdiana; daí a necessidade de mudança 
do meio envolvente das empresas e instituições e a necessidade de se adaptarem à nova ordem mundial.

O volume contém informações sobre cerca de 3.000 empresas e instituições, valiosas para todos aqueles que pretendam conhecer o tecido empresarial de Cabo Verde. Nas páginas 10 e 11, o leitor encontrará pequenas breves notas sobre o País (geografia, história, população, economia), seguindo-se ligeiros apontamentos de cada uma das ilhas, ilustrados com belíssimas fotografias a cores (pp. 12-24); as páginas 35 a 106 são preenchidas com a apresentação de anúncios das empresas e instituições. Não deixa de ser interessante sublinhar a cuidadosa apresentação do caderno dedicado às Canárias (pp. I-XII), com informações sintéticas sobre a situação política, os aspectos geográficos, a economia, as infra-estruturas físicas, as telecomunicações, a formação universitária e profissional, o regime económico e fiscal, as formas de intercâmbio comercial com Cabo Verde, etc. e 7 quadros com dados estatísticos (geralmente 1991-2001) sobre população, o emprego por sectores, tráfico aéreo, tráfico marítimo, balança comercial e turismo.

Outra publicação de interesse é o Guia das ONG (224p.), em edição bilingue, português e francês, preparado pela respectiva Plataforma. Ficamos a saber que existiam cerca de oitenta ONG de desenvolvimento e quase seiscentos agrupamentos associativos, entre os quais se inclui a Associação de Geógrafos Cabo-verdianos, criada em 2002. A apresentação da Plataforma (pp. 15-19) é feita por pequenas notas acerca da sua constituição e objectivos, do reconhecimento como pessoa jurídica, estrutura e organização, membros, alguns eixos estratégicos, domínios de actuação e actividades, e parceiros da Plataforma. Antes deste Guia já tinham sido produzidos outros documentos como o Desdobrável de apresentação da Plataforma, o Estudo sobre as necessidades das ONG em matéria de formação, o Manual sobre o enquadramento jurídico das ONG, o Resumo da análise da situação actual das ONG em Cabo Verde - documentos disponíveis na Plataforma mediante um simples pedido (Fax (238) 617 845, e-mail: platongsacv@telecom.cv). O Guia surge no momento em que o movimento associativo atingiu o ponto alto da sua dinâmica em termos de crescimento quantitativo, embora ainda requeira crescimento qualitativo.

Segundo palavras do Secretário Geral da Plataforma a edição do Guia está na base de três objectivos essenciais: contribuir para um melhor conhecimento da realidade da família ONG em Cabo Verde; reforçar a comunicação e a cooperação entre as ONG e entre estas e as demais Organizações da Sociedade Civil, com vista à aprendizagem e reforço mútuos; e divulgar informações sobre as actividades das ONG junto dos seus parceiros e potenciais parceiros, sejam eles Governamentais e Não Governamentais, a nível nacional e internacional.

A primeira parte do Guia encerra com notas gerais sobre a situação das ONG em Cabo Verde (pp. 21-24). A segunda é constituída por fichas descritivas das ONG, onde estão devidamente identificadas (nome, abreviatura, nacionalidade, endereços, pessoas de contacto, natureza jurídica); informações sobre a organização interna e funcionamento (número de membros, percentagem de mulheres, responsáveis, órgãos sociais, comissões de trabalho, pessoal permanente); informações sobre domínios de intervenção e tipos de actividades, áreas geográficas de actuação, principais grupos sociais beneficiários e publicações; filiações e parceiros (fontes de funcionamento, data de entrada na Plataforma, filiação noutras organizações). Uma tabela sintética resume as informações do estado dos membros da Plataforma em 15 de Novembro de 2001. Segue-se a transcrição de legislação aplicável a associações, contactos úteis, gráficos e quadros de distribuição das ONG. É, certamente, um documento muito útil. 
Terminamos estas notas referenciando dois documentos de interesse relacionados com os problemas de mudanças climáticas: Comunicação Nacional - Mudanças climáticas (Praia, 1999, 93 p.) e Estratégia nacional e plano de acção sobre mudanças climáticas (Praia, 2000, 118 p.), com muitos quadros estatísticos e algumas figuras, ambos produzidos pelo Secretariado Executivo para o Ambiente, sediado no Ministério da Agricultura, Alimentação e Ambiente.

Perante a evidência de que o ambiente global se tem modificado por alterações climáticas profundas, que está sob uma forte pressão de actividades humanas, há hoje um amplo consenso entre a comunidade científica e os responsáveis políticos mundiais de que aquelas actividades podem estar a contribuir para uma mudança climática global sem precedentes, pois as emissões de gases com efeitos de estufa estão a contribuir para o aquecimento global à superfície da Terra.

Assinada em Junho de 1992, na Cimeira da Terra no Rio de Janeiro, a Convenção Quadro das Nações Unidas sobre as mudanças climáticas, a ratificação de Cabo Verde foi em 29 Março 1995, assumido os compromissos de organizar uma Comissão Nacional a quem compete a elaboração da Estratégia Nacional e Plano de Acção para a implementação daquela Convenção. Nos dois documentos acima mencionados foram tidos em conta os diversos estudos efectuados em diferentes sectores, sublinhadas as preocupações com a realidade do país no seu processo de desenvolvimento, dos seus problemas de vulnerabilidade, e possível adaptação, relatando todos os procedimentos relacionados com a emissão de gases com efeitos de estufa. Os documentos contêm projecções de cenários de emissão, propõem políticas e medidas de atenuação e analisam as necessidades básicas respeitantes a recursos técnicos e financeiros para o desenvolvimento e implementação do Plano Nacional de Mitigação, bem como as necessidades de assistência técnica de organismos internacionais, a fim de levar a bom termo o que está convencionado.

No primeiro volume estão as características do país (físicas, humanas, económicas, etc.); o resumo do inventário das emissões de gases com efeitos de estufa; as políticas e medidas para a redução de tais gases e respectivos efeitos; a projecção das suas emissões por sectores de actividade; a vulnerabilidade e adaptação; as necessidades de assistência técnica, financeira e de transferência de tecnologia; a investigação sistemática; a educação e a formação; conclusões; glossário e bibliografia. Em anexos há quadros estatísticos - pecuária, produção das principais culturas e a sua evolução, áreas florestadas, importação de butano, energia produzida e distribuída, evolução do número total de viaturas, quantidades de fertilizantes azotados, utilizadas para o cálculo das emissões de $\mathrm{N}_{2} \mathrm{O}$, cálculos das emissões de metano a partir dos animais domésticos e de adubos azotados, etc. No segundo volume as matérias estão arrumadas nas seguintes partes: oportunidades e desafios; mudanças climáticas e o desenvolvimento sócio-económico e ambiental; estratégia nacional e plano de acção. Contém ainda fichas de projecto, glossário e bibliografia. 
